\title{
A palimpsest grave at the Iron Age cemetery in Estark-Joshaqan, Iran
}

\author{
Javad Hosseinzadeh ${ }^{1, *}$, Mohsen Javeri ${ }^{1}$, Majid Montazerzohouri ${ }^{1}$, \\ Ali Banitaba ${ }^{2}$, Reza Nori Shadmahani ${ }^{1}$, Leila Makvandi ${ }^{1}$ \\ \& Arkadiusz Sołtysiak ${ }^{3, *}$
}

At the onset of the Iron Age, after c. 1200 BC, Iran was a place of major social transformation. After the collapse of the Bronze Age urban civilisations, the land was inhabited mainly by groups of mobile pastoralists that gradually transitioned from tribal organisation into loose federations, before finally developing into the Median and Persian early states (Potts 2014). This transition is still poorly recognised, as settlement sites from this period are scarce and most evidence is from cemeteries that were excavated many decades ago. Here we report results of excavations at a recently discovered cemetery that may provide new insights into the social complexity and cultural affinities of Iron Age nomads in Iran.

Estark-Joshaqan is an Iron Age cemetery in one of the easternmost valleys of the Karkas Mountains, approximately $10 \mathrm{~km}$ west of the city of Kashan $\left(34^{\circ} 01^{\prime} 24^{\prime \prime} \mathrm{N}, 51^{\circ} 13^{\prime} 51^{\prime \prime} \mathrm{E}\right.$, $1300 \mathrm{~m}$ asl). The site is located on a quaternary alluvial terrace and covers less than 1 ha. During the autumn of 2016, a rescue project was launched to document burials being destroyed by looting and agricultural activities, and to excavate a $5 \times 5 \mathrm{~m}$ trench near the least damaged, north-western limit of the site (Figure 1).

Artefacts and fragments of bone were initially collected from an area of 46 looting pits. The material retrieved, including ceramic sherds, metal fragments and a broken cylinder seal, is consistent in chronology and analogous with material from Tepe Sialk and other sites in the region. The finds could therefore be dated to the Iron Age II (c. 1000-800 BC) (Ghirshman 1939; Overlaet 2003). Human bone fragments, although heavily eroded, suggest that the common burial rite was individual inhumation in chambers made of large stones (Sołtysiak et al. 2016).

The test trench revealed one complete oval stone structure (grave) and a part of another that has not been fully explored (Figure 2). The dimensions of the oval grave are around $3.5 \mathrm{~m}$ on a south-east to north-west axis and about $2.5 \mathrm{~m}$ on a north-east to south-west axis. Adjacent to its north-east wall was an irregular pit (A) filled with pebbles, potsherds, ashes and cremated human and animal bones. Another pit (B), approximately $1 \mathrm{~m}$ in diameter and around $1 \mathrm{~m}$ in depth, cut the north-west inner part of the grave. Ashes, cremains and

\footnotetext{
Department of Archaeology, University of Kashan, Qotbe Ravandi Boulevard, Kashan, Iran

Department of Mining, University of Kashan, Qotbe Ravandi Boulevard, Kashan, Iran

Department of Bioarchaeology, Institute of Archaeology, University of Warsaw, ul. Krakowskie Przedmiescie 26/28, 00-927 Warszawa, Poland

* Authors for correspondence (Email: javadhoseinzadeh@gmail.com; a.soltysiak@uw.edu.pl)
} 


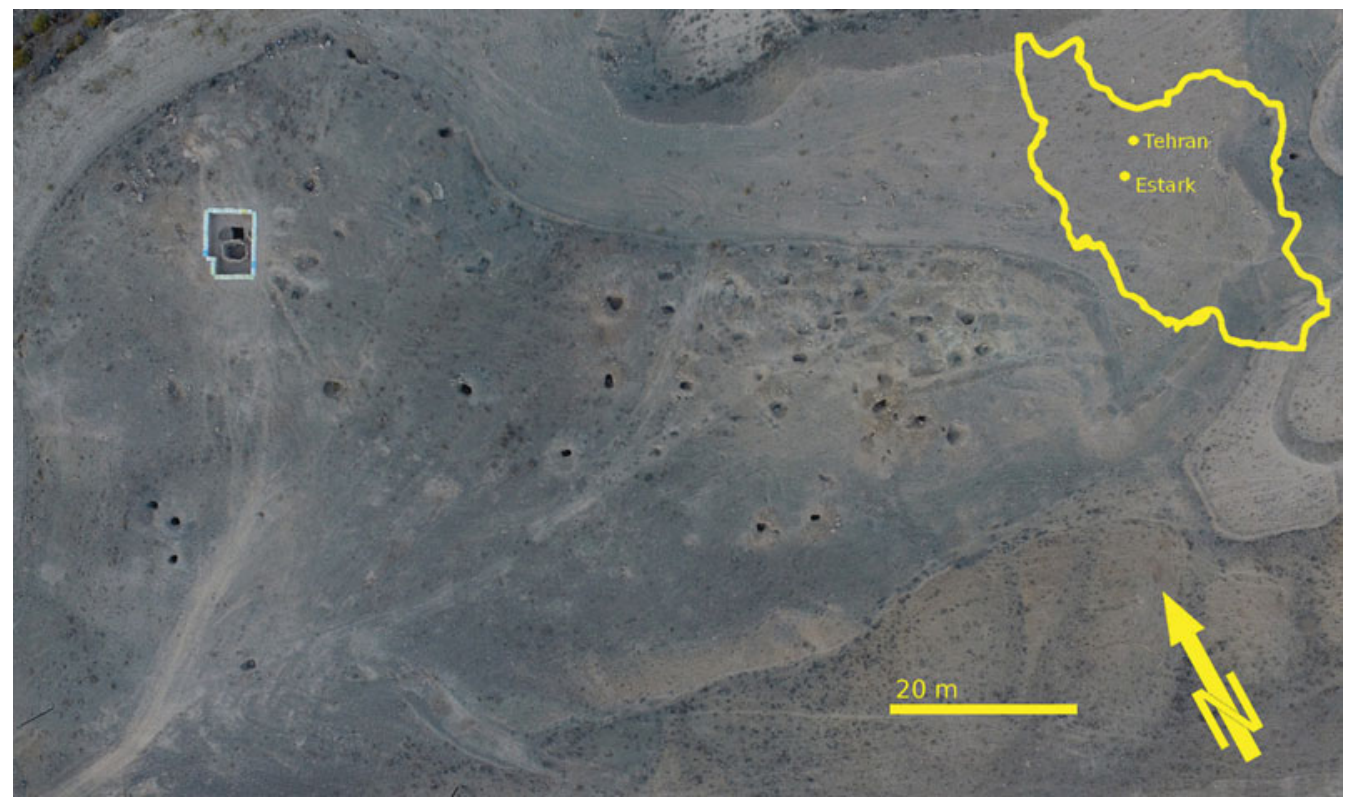

Figure 1. Aerial photograph of the cemetery.

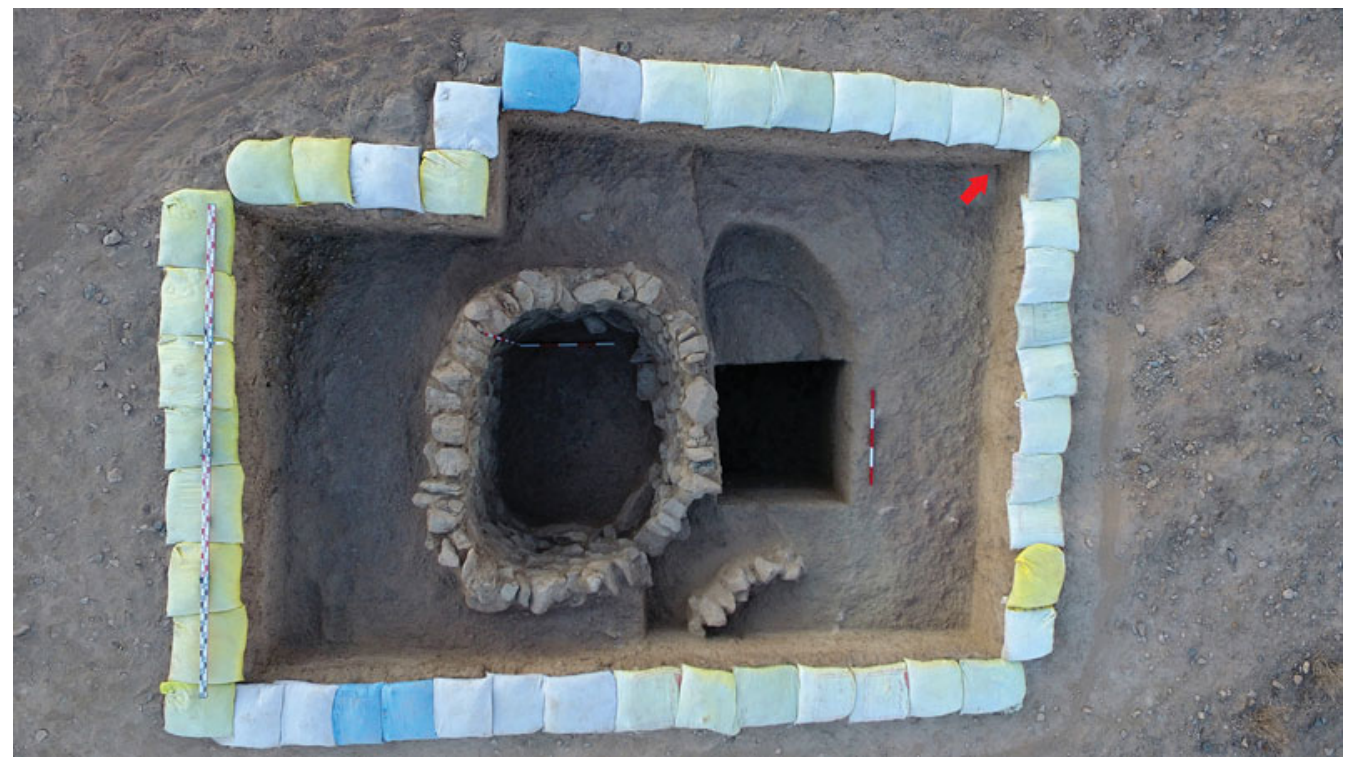

Figure 2. Excavation area at Estark following complete exploration of the oval grave.

potsherds were also abundant here, but only in the lower part of the pit. As many sherds from both pits came from the same individual vessels, and as the pattern of cremation was similar, pit A probably contained material that had been removed from the upper part of pit B. Cremains from these pits represented at least 13 individuals of varied sex and age at death (Sołtysiak et al. 2016).

(C) Antiquity Publications Ltd, 2017 


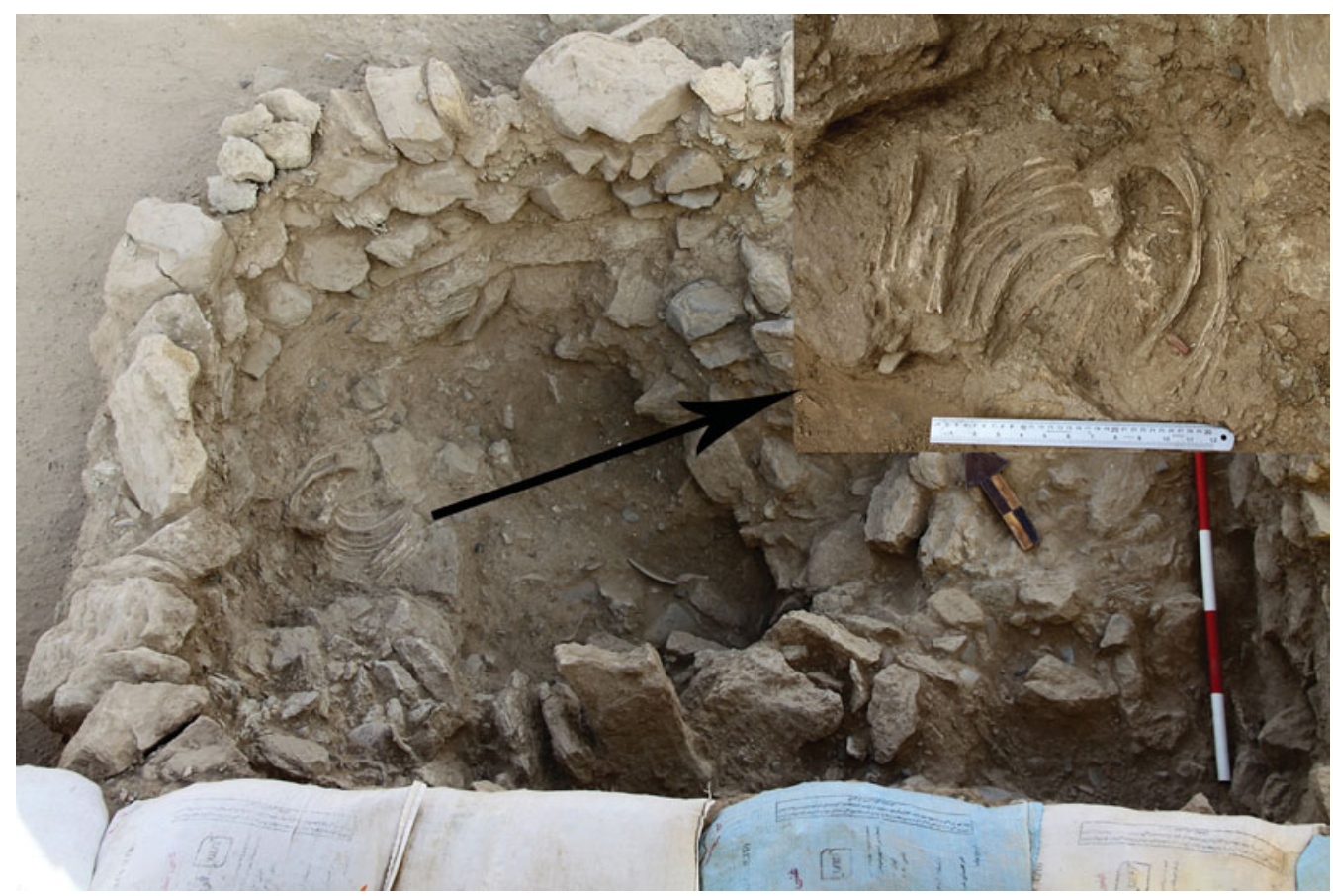

Figure 3. Partially articulated skeleton close to the north-west wall of the oval grave.

In the upper part of the south-east fill of the grave there was a dense concentration of potsherds above an irregular layer of stone that contained a few disarticulated (but not cremated) bones of an adult male. Below the latter was a thick layer (around $0.6 \mathrm{~m}$ ) of large limestone cobbles that appear to have formed the original floor of the grave, although this floor was partially destroyed by the cut of pit B. Along the north-west wall, on the floor of the grave, the partially preserved upper part of an articulated human skeleton was discovered. The lower part of this individual was truncated by pit B. This skeleton was much more gracile than the disarticulated bones found in the south-east part of the oval grave, and probably represented an older female (Figure 3). Surprisingly, disarticulated human remains (not cremated) were also found below the original floor of the stone structure, placed on the natural soil. They were accompanied by five crushed ceramic vessels, bronze objects and shell beads.

In total, more than 9000 potsherds were retrieved from the test trench, with more than 6000 from the inner part of the oval grave. They represented more than 100 vessels, including 30 that were restored to more than 80 per cent of their original state (Figure 4). Most vessels (around 80 per cent) were grey wares, and the rest were red, except for three pieces that were painted with red and brown geometric motifs. Some of the pots were decorated with incised geometric patterns. Of the various types of vessels, the main categories were single- or double-handled cups, small-, medium- and large-sized bowls, jars and beakers, 'tripod echinus' bowls, horizontal- and vertical-handled pots, and cooking pots. All of these are typical of Iron Age II ceramic assemblages. 


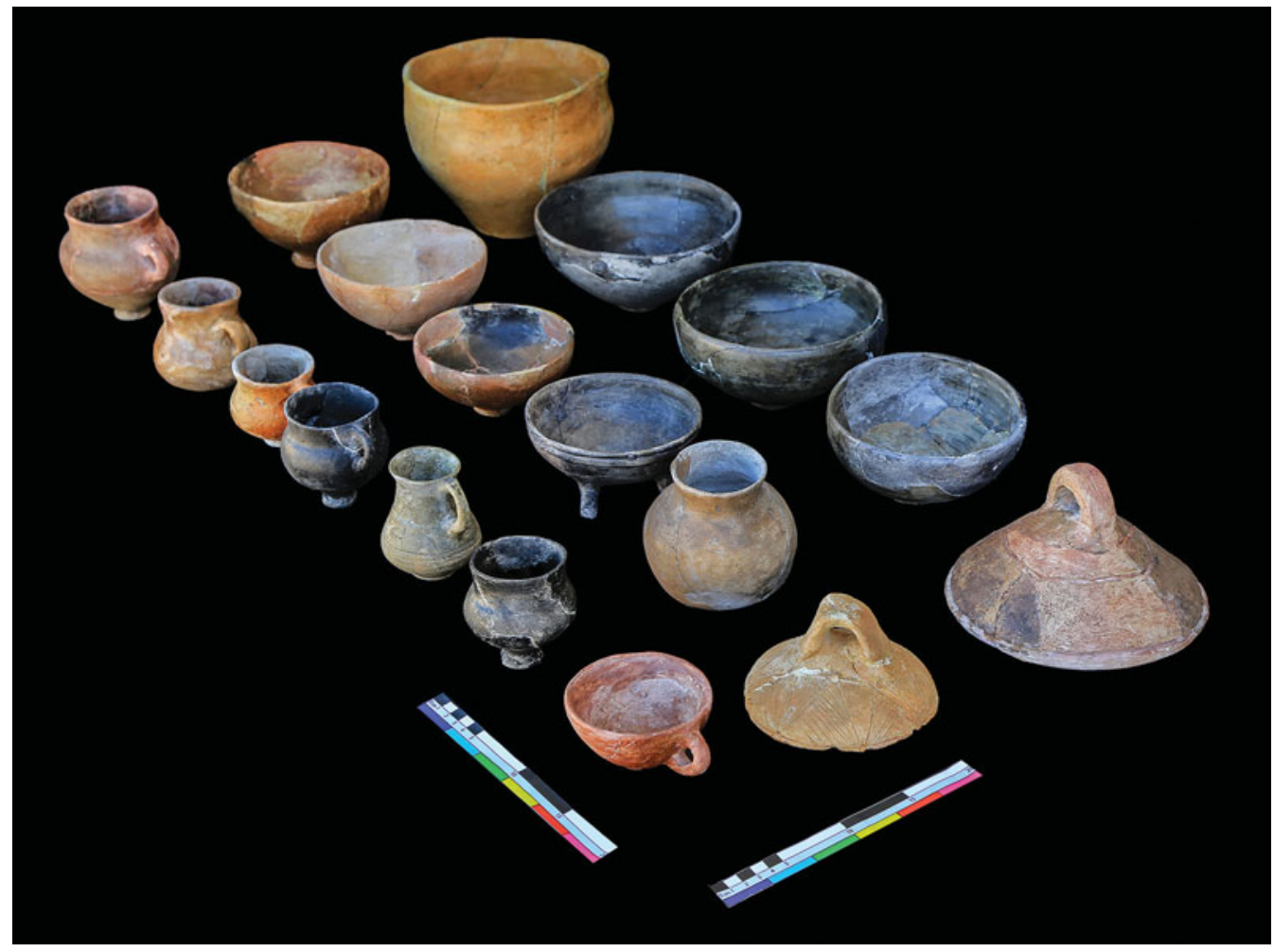

Figure 4. Reconstructed pots from the oval grave.
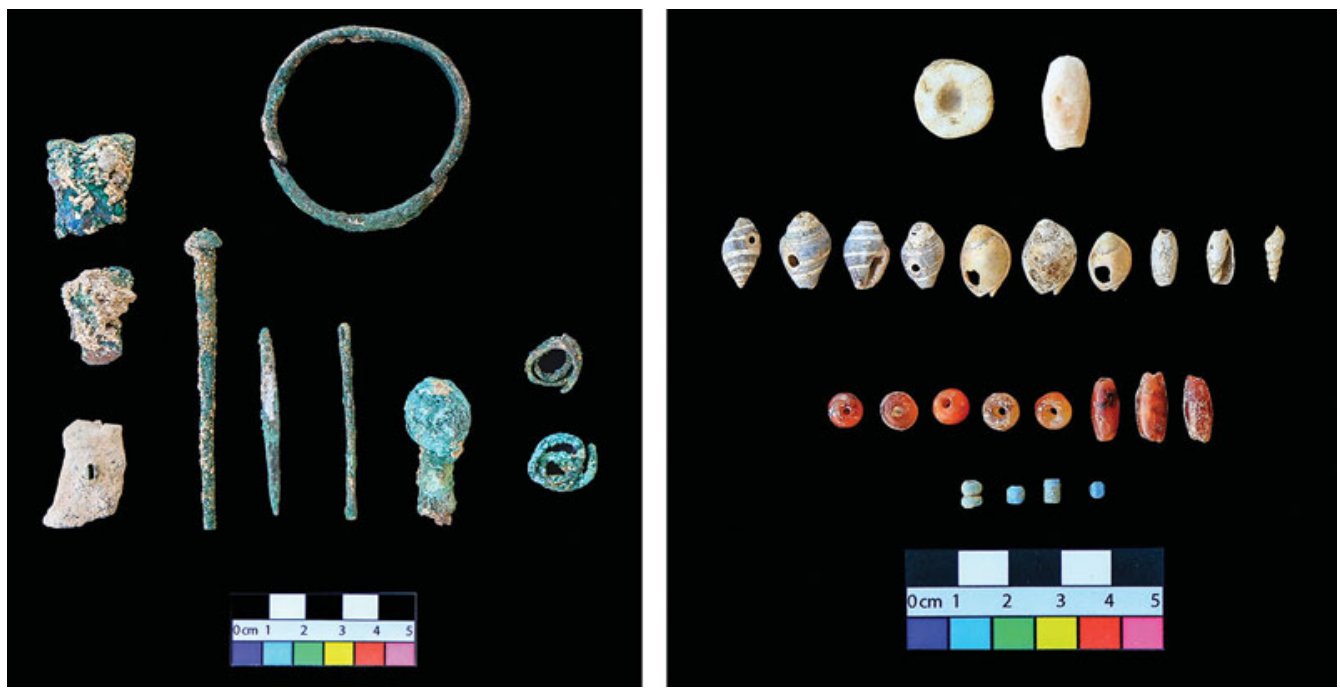

Figure 5. Metal artefacts and beads from the oval grave.

(C) Antiquity Publications Ltd, 2017 
A palimpsest grave at the Iron Age cemetery in Estark-Joshaqan, Iran
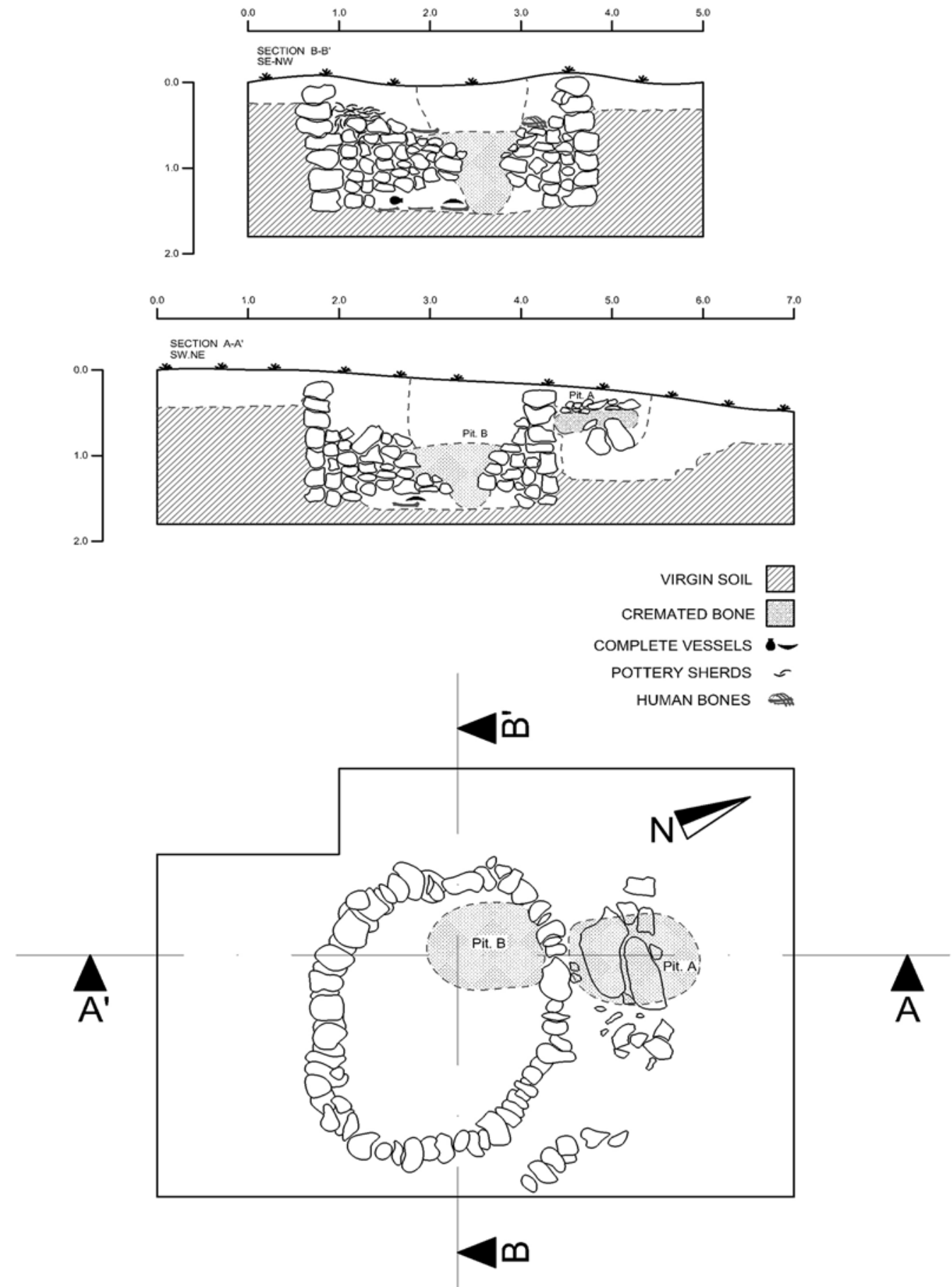

Figure 6. Schematic stratigraphy of the oval grave and its surroundings.

(C) Antiquity Publications Ltd, 2017 
The bronze objects found in the oval grave and on the surface, all of them fragmentary, are from various personal ornaments, such as earrings, bracelets, rings and hair pins. Several limestone, agate and shell beads were also found inside the main stone structure (Figure 5). Some of these beads were closely associated with human remains, while some were intermingled with pebbles. Accidental distribution of these beads throughout the grave indicates that it was disturbed in antiquity.

Considering all the evidence, a possible sequence for the complex stratigraphy of the oval grave can be proposed. First, a large grave (phase 1) was dug into the ground and a secondary inhumation of an individual body with completely disarticulated bones was placed at the bottom. Next (phase 2), a stone floor was built above this grave, and the oval stone chamber was constructed as the burial place for one or two individuals-a possible female and a physically more robust male. This burial was probably looted in antiquity, as indicated by the scattered pottery and complete disarticulation of bones found in the south-east part of the grave. At the next stage, pit B (phase 3) was cut into the north part of the burial chamber and the cremains of at least 13 human individuals and some animals were deposited in it. Finally (phase 4), the upper part of pit $B$ and the associated original fill of the stone chamber grave (phase 2) were moved to another pit (A), outside the oval structure (Figure 6).

Such a sequence of use is unusual for a burial site of the Iranian Iron Age, where singleinhumation chambered burials dominate, with no recorded evidence of cremation. At Estark-Joshaqan, the sequence of inhumation burials may be easily explained—an older grave was moved to a new burial (phase 1) and then looting disturbed the newer (phase 2) burial(s). Nonetheless, the presence of collective cremains in two sequential pits-one inside and one outside the previous stone structure-is puzzling.

During roughly the same period, bodies were occasionally cremated in northern Mesopotamia, where this tradition spread from the Hittites or the Sea People. These cremains, however, usually represented one individual skeleton contained in a ceramic vessel (Ferreri 2015). The most direct analogies of collective cremains are noted farther north of Iran and are associated with the Colchian culture in Georgia, or the Andronovo culture in Central Asia (Gorjachev \& Mar'jashev 1998; Gobejishvili 2014). The unusual grave at Estark-Joshaqan may, therefore, be the evidence of a new tradition that originated in the steppe areas north of the Caspian and Black Seas and was transferred to Iran during the Iron Age. As heavily fragmented and commingled human remains are also reported at Dinkha Tepe (Muscarella 1968), it is possible that cremation played a more significant role during that time in Iran, and that previous archaeological work has failed to recognise properly the presence and significance of cremains.

\section{References}

FERreri, S. 2015. Cremation burials in north Mesopotamia in the first millennium BC: evidence of social differentiation in the Assyrian Empire? Unpublished MPhil dissertation, University of Cambridge.
Ghirshman, R. 1939. Fouilles de Sialk pres de Kashan, 1933, 1934, 1937 (volume 2). Paris: Librairie Orientaliste Paul Geuthner.

Gobejishvili, N. 2014. Interrelation of Colchian and Koban cultures according to burial constructions and funerary customs (Late Bronze to Early Iron Age). Spekali 8: 1-13. 
Gorjachev, A.A. \& A.N. Mar'Jashev. 1998.

Nouveaux sites du Bronze récent au Semirech'e (Kazakhstan). Paléorient 24: 71-80.

https://doi.org/10.3406/paleo.1998.4670

Muscarella, O.W. 1968. Excavations at Dinkha Tepe 1966. The Metropolitan Museum of Art Bulletin 27: 187-96. https://doi.org/10.2307/3258385

OverLaet, B. 2003. The Early Iron Age in the Pusht $-i$ Kuh, Luristan (Luristan Excavation Documents 4). Leuven: Peeters.
Pоттs, D.T. 2014. Nomadism in Iran. From antiquity to the modern era. Oxford: Oxford University Press. https://doi.org/10.1093/acprof:oso/ 9780199330799.001.0001

Soltysiak, A., J. Hosseinzadeh, M. JaVeri $\&$ M. Montazerzohouri. 2016. Human remains from Estark, Iran, 2016. Bioarchaeology of the Near East 10: 75-81. 